\title{
THE EFFECT OF SUPERNUMERARY HETEROCHROMATIC CHROMOSOME SEGMENTS ON NON-HOMOLOGOUS CHROMOSOME ASSOCIATIONS IN THE GRASSHOPPER CAMULA PELLUCIDA
}

\author{
KATHLEEN CHURCH \\ Department of Zoology, Arizona State University, Tempe, Arizona 85281
}

Received 8.x.73

\begin{abstract}
SUMmary
The effect of a supernumerary heterochromatic segment on non-homologous chromosome associations has been investigated in the grasshopper Camula pellucida. A supernumerary segment located in one of the smallest chromosomes of the complement is associated with a substantial increase in the frequency of non-homologous chromosome associations at diplotene of meiosis. Bivalents that are segmented enter into more non-homologous chromosome associations than non-segmented bivalents. The non-homologous associations are completely resolved prior to metaphase II of meiosis. Both segmented and non-segmented chromosomes are randomly arranged in the radial metaphase II configuration.
\end{abstract}

\section{INTRODUCTION}

POLYMORPHISMS involving supernumerary heterochromatic chromosomal segments occur commonly among Orthoptern insects (John and Hewitt, 1966; Hewitt and John, 1968; Westerman, 1969; Shaw, 1970). A consistent phenotypic effect associated with the presence of the segments is an effect on chiasma conditions during meiosis (John and Hewitt, 1969; Westerman, 1969; Shaw, 1971). In those species that have been analysed, the supernumerary heterochromatin is associated with a rise in the mean cell chiasma frequency.

Such a polymorphism was discovered in two populations of the grasshopper Camula pellucida in the summer of 1972. This system involves a supernumerary segment present in a distal position on one of the smallest chromosomes of the complement. The population is composed of individuals with the standard basic karyotype $(B B)$, and individuals that are heterozygous $(B S)$ for the segment. If homozygotes $(S S)$ occur they are rare, since I have yet to encounter one. The segment segregates reductionally at anaphase I in 98 per cent of the cells (Church, unpublished) and preliminary evidence indicates that it is associated with a rise in the mean cell chiasma frequency.

The present report describes the effect of the segment on non-homologous chromosome associations at diplotene of meiosis, and on the arrangement of chromosomes in the radial metaphase II configuration.

\section{Methods and materials}

Grasshoppers were collected from an area located 30 miles northeast of Payson, Arizona during June of 1972. 
Testes were removed from the animals and fixed in $3: 1$ ethanol to glacial acetic acid for 3 hours prior to storage in 70 per cent ethanol. The testes were subsequently squashed in lacto-propionic orcein.

\section{Observations}

The standard male chromosome complement at diplotene consists of 11 bivalents and the univalent $\mathrm{X}$ chromosome. The heterochromatic $\mathrm{X}$ chromosome and the nucleolar organising (NO) bivalent can be easily recognised in all cells in diplotene. The NO bivalent is the third smallest bivalent of the complement and is largely heterochromatic. The two smallest bivalents $\left(\mathrm{S}_{1}\right.$ and $\left.\mathrm{S}_{2}\right)$ can be distinguished from other bivalents in the cell but they cannot be distinguished from each other. The remaining bivalents range in size from large to medium and cannot be recognised with regularity (plate I, fig. 1). All bivalents show a small block of procentric heterochromatin in favourable preparations. From a sample of 37 individuals, 32 displayed the standard karyotype.

Five of the 37 individuals contained a supernumerary heterochromatic segment in the heterozygous condition. This segment is located in a distal position on one of the two smallest bivalents. Thus, in segmented individuals it is possible to distinguish the two small bivalents from each other (plate I, figs. 3 and 4). In all other respects the segmented karyotype is identical to the standard karyotype.

\section{(i) The analysis of cells in diplotene}

The present analysis includes only the $\mathrm{X}$ chromosome, the NO bivalent, and the two small bivalents because they are the only nuclear elements that can be definitely recognised in all cells in diplotene. One hundred cells in diplotene from each of five animals with the standard karyotype were analysed to determine the types and frequencies of non-homologous associations involving these chromosomes. For example, a situation where the $\mathrm{X}$ chromosome was touching the NO bivalent was recorded as an X-NO association. Other possible associations include: X-S, NO-S, S-S. Multiple associations include X-NO-S-S. The results of this analysis are recorded in

TABLe 1

Types and frequencies of non-homologous associations involving the $X$ chromosome, the NO bivalent and the two small bivalents in five individuals with the standard, non-segmented karyotype. Cells were observed at mid-diplotene of meiosis

\begin{tabular}{|c|c|c|c|c|c|c|c|}
\hline \multirow{2}{*}{$\begin{array}{c}\text { Male } \\
\text { no. }\end{array}$} & \multirow{2}{*}{$\begin{array}{l}\text { No. of } \\
\text { cells } \\
\text { observed }\end{array}$} & \multicolumn{5}{|c|}{ Types and frequencies of associations } & \multirow[b]{2}{*}{ Total } \\
\hline & & X-NO* & $\left(\mathrm{S}_{1}-\mathrm{X} \mathrm{S}_{2}-\mathrm{X}\right) \dagger$ & $\left(\mathrm{S}_{1}-\mathrm{NO} S\right.$ & $\left.\mathrm{S}_{2}-\mathrm{NO}\right) \dagger$ & $\left(\mathrm{S}_{1}-\mathrm{X}-\mathrm{NO} \mathrm{S}_{2}-\mathrm{X}-\mathrm{NO}\right)$ & \\
\hline la & 100 & 13 & 8 & $\begin{array}{lll}-1 & 1\end{array}$ & 1 & 1 & 23 \\
\hline $2 a$ & 100 & 8 & 3 & & 1 & 0 & 12 \\
\hline $3 a$ & 100 & 11 & 2 & & 1 & 0 & 14 \\
\hline $4 a$ & 100 & 7 & 3 & & 1 & 0 & 11 \\
\hline $5 a$ & 100 & 16 & 5 & & 0 & 0 & 21 \\
\hline \multirow[t]{2}{*}{ Total } & 500 & 55 & 21 & & 4 & 1 & 81 \\
\hline & Percentage & $11 \cdot 0$ & $4 \cdot 2$ & & $0 \cdot 8$ & $0 \cdot 2$ & 16.2 \\
\hline
\end{tabular}


table 1. A total of $16 \cdot 2$ per cent of the cells showed some type of nonhomologous association involving the $\mathrm{X}$ chromosome, the NO bivalent and the two small bivalents. The majority of these associations (11 per cent) were of the X-NO type (plate I, figs. 1 and 2). The X chromosome was associated with a small bivalent in 4.2 per cent of the cells. Other types of associations occurred much less frequently (S-NO, S-X-NO) or not all (S-S; S-S-X-NO).

A similar analysis was performed on five individuals that contained the supernumerary heterochromatic segment. In these animals it is possible to distinguish between the two smallest bivalents due to the presence of the segment in one of the bivalents (plate I, figs. 3 and 4). Again associations were observed in various arrangements involving the $\mathrm{X}$ chromosome, the NO bivalent, the segmented small bivalent $\left(S_{1}\right)$ and the non-segmented small bivalent $\left(\mathrm{S}_{2}\right)$ (table 2). It is obvious that a greater proportion of the cells from segmented individuals ( 38 per cent) display non-homologous

TABLE 2

Types and frequencies of non-homologous associations involving the $X$ chromosome, the $\mathcal{N} O$ bivalent and the two small bivalents in five individuals with the segmented karyotype. Cells were observed at mid-diplotene of meiosis

\begin{tabular}{|c|c|c|c|c|c|c|c|c|c|}
\hline \multirow{3}{*}{$\begin{array}{c}\text { Male } \\
\text { no. } \\
\text { lb }\end{array}$} & \multirow{3}{*}{$\begin{array}{c}\text { No. of } \\
\text { cells } \\
\text { observed } \\
100\end{array}$} & \multicolumn{7}{|c|}{ Types and frequencies of associations } & \multirow[b]{2}{*}{ Total } \\
\hline & & $\mathrm{X}-\mathrm{NO}$ * & $\mathrm{S}_{1}-\mathrm{X} t$ & $S_{2}-X_{\dagger}^{+}$ & $\mathrm{S}_{1}-\mathrm{NO}$ & $\mathrm{S}_{2}-\mathrm{NO}$ & $\mathrm{S}_{1}-\mathrm{X}-\mathrm{NO}$ & $\mathrm{S}_{2}-\mathrm{X}-\mathrm{NO}$ & \\
\hline & & 15 & 11 & 5 & 4 & 1 & 1 & 0 & 37 \\
\hline $2 \mathrm{~b}$ & 100 & 14 & 7 & 3 & 3 & 3 & 4 & 0 & 34 \\
\hline $3 \mathrm{~b}$ & 100 & 9 & 12 & 6 & 2 & 1 & 1 & 0 & 31 \\
\hline $4 \mathrm{~b}$ & 100 & 19 & 15 & 2 & 4 & 0 & 3 & 0 & 43 \\
\hline $5 b$ & 100 & 13 & 17 & 1 & 10 & 1 & 3 & 0 & 45 \\
\hline Totals & 500 & 70 & 62 & 17 & 23 & 6 & 12 & 0 & 190 \\
\hline & Percentage & $14 \cdot 0$ & $12 \cdot 4$ & $3 \cdot 4$ & $4 \cdot 6$ & $1 \cdot 2$ & $2 \cdot 4$ & 0 & 38 \\
\hline
\end{tabular}

* X-NO number of cells in which the X chromosome touches the NO bivalent.

i $S_{1}$ and $S_{2}$ refer to the segmented small bivalent and the non-segmented small bivalent respectively.

chromosome associations when compared with cells from individuals with the standard karyotype (16.2 per cent). The frequency with which the $\mathrm{X}-\mathrm{NO}$ association occurs is similar in the two groups, but there the similarity ends (compare tables 1 and 2). The total percentage of cells from the standard individuals where small bivalents entered into a non-homologous association was 5.2 per cent as compared with 24 per cent in segmented individuals. Furthermore, the increase appears to be accounted for by the behaviour of the segmented small bivalent which associated with the $\mathrm{X}$ chromosome in 12.4 per cent of the cells and with the NO bivalent in 4.6 per cent of the cells (table 2; plate I, figs. 3 and 4).

These results clearly indicate that the presence of the supernumerary heterochromatic segment increases the probability that the small bivalent will enter into non-homologous associations during prophase of meiosis.

\section{Analysis of cells in metaphase II}

This analysis was performed to determine if the presence of the supernumerary heterochromatic segment affects the arrangement of chromo- 
somes at meiotic stages subsequent to diplotene. The rationale was as follows: if non-homologous associations persist to any degree beyond prophase stages, one might expect this to be reflected in the arrangement of those chromosomes at later stages. For example, the segmented small bivalent is frequently associated with the $\mathrm{X}$ chromosome at diplotene. If such associations were not fully resolved they could cause these two cellular elements to lie close together in subsequent stages.

An analysis similar to that performed by Nur (1973) was utilised. In his analysis, Nur (1973) determined that in the grasshopper Melanoplus femur-rubrum, the large chromosomes were randomly positioned with respect to the medium sized chromosomes on the radial metaphase II configuration. I used the analysis to determine if the two smallest chromosomes were randomly positioned at metaphase II with respect to all other chromosomes in both segmented and non-segmented individuals. If the supernumerary heterochromatin has an effect on the positioning of the small chromosome then a departure from randomness in the arrangement of the radial metaphase II chromosomes in segmented individuals is expected.

Preparations obtained from both segmented and non-segmented individuals were scanned for cells which displayed a radial metaphase II configuration. Only those cells which showed a near perfect circle including all chromosomes were used in the analysis. In all preparations, the two smallest chromosomes were easily identified (plate I, figs. 5 and 6). The number of chromosomes separating the two smallest chromosomes were determined in both directions of the circle (Plate I, figs. 5 and 6). Cells which contain the $\mathrm{X}$ chromosome have 10 chromosomes excluding the two small chromosomes (fig. 5), and cells without the $X$ have 9 (fig. 6). If the small chromosomes are positioned randomly in the configuration with respect to all other chromosomes one would expect to observe a $0-10$, $1-9,2-8,3-7,4-6,5-5$ arrangement in a $1: 1: 1: 1: 1: 1 / 2$ ratio in cells containing an $\mathrm{X}$. For cells without the $\mathrm{X}$, the expected classes would be $0-9,1-8,2-7,2-7,3-6,4-5$ in a $1: 1: 1: 1: 1$ ratio. The results (tables 3 and 4) indicate that the two small chromosomes are randomly arranged with respect to all other chromosomes at metaphase II of meiosis in both segmented and non-segmented individuals. It appears that the presence of the super-

TABLE 3

Arrangement of small-sized chromosomes at metaphase II in individuals with the standard karyotype. Values were obtained by counting the number of chromosomes separating the two small chromosomes in both directions of the radial metaphase configuration

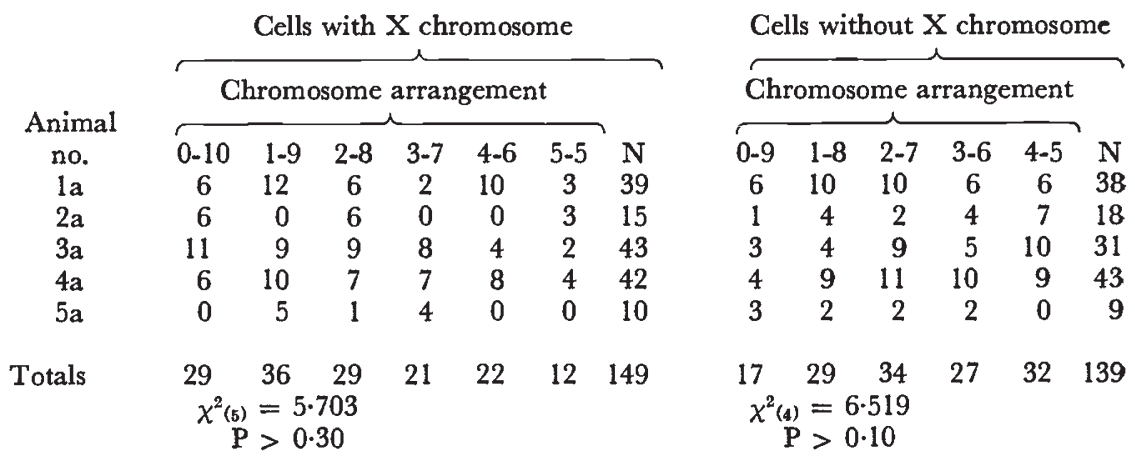




\section{TABLE 4}

Arrangement of small-sized chromosomes at metaphase II in individuals with the segmented karyotype. Values were obtained by counting the number of chromosomes separating the two small chromosomes in the directions of the radial metaphase configuration

\begin{tabular}{|c|c|c|c|c|c|c|c|c|c|c|c|c|c|}
\hline \multirow{4}{*}{$\begin{array}{c}\text { Animal } \\
\text { no. } \\
\text { lb }\end{array}$} & \multicolumn{7}{|c|}{ Cells with $\mathrm{X}$ chromosome } & \multicolumn{6}{|c|}{ Cells without $\mathrm{X}$ chromosome } \\
\hline & \multicolumn{6}{|c|}{ Chromosome arrangement } & \multirow[b]{2}{*}{$\mathrm{N}$} & \multicolumn{6}{|c|}{ Chromosome arrangement } \\
\hline & $0-10$ & $1-9$ & $2-8$ & $3-7$ & $4-6$ & $5-5$ & & 0.9 & $1-8$ & $2-7$ & $3-6$ & $4-5$ & $\mathrm{~N}$ \\
\hline & 0 & 7 & 6 & 12 & 2 & 4 & 31 & 8 & 12 & 2 & 0 & 6 & 28 \\
\hline $2 \mathrm{~b}$ & 6 & 9 & 5 & 2 & 14 & 0 & 36 & 5 & 1 & 7 & 8 & 8 & 29 \\
\hline $3 b$ & 4 & 6 & 9 & 2 & 0 & 1 & 22 & 0 & 4 & 4 & 2 & 7 & 17 \\
\hline $4 b$ & 10 & 11 & 3 & 8 & 5 & 0 & 37 & 10 & 11 & 12 & 7 & 13 & 53 \\
\hline $5 b$ & 0 & 5 & 2 & 2 & 6 & 3 & 18 & 6 & 2 & 2 & 8 & 2 & 20 \\
\hline Totals & $\begin{array}{l}20 \\
\chi^{2}(5) \\
P\end{array}$ & $\begin{array}{l}38 \\
=8 . \\
>0 .\end{array}$ & & 26 & 27 & 8 & 144 & $\begin{array}{l}29 \\
\chi^{2}(4) \\
\mathrm{P}\end{array}$ & $\begin{array}{l}30 \\
=2 . \\
>0\end{array}$ & & 25 & 36 & 147 \\
\hline
\end{tabular}

numerary segment has no effect on the arrangement of chromosomes at metaphase II of meiosis.

\section{Discussion}

A characteristic of heterochromatin well described by Vanderlyn (1949) in his extensive review on the subject was that it tended to "flow or clump together". Many descriptions of non-homologous associations between heterochromatic regions of chromosomes during prophase of meiosis occur in the literature (e.g. Darlington, 1936; Southern, 1967). Darlington's description of these associations in the grasshoppers Chorthippus and Stauroderus is particularly detailed. During pachytene of meiosis, heterochromatic ends of chromosomes may become attached to the $\mathrm{X}$ and the two most condensed bivalents often associate with the $\mathrm{X}$ chromosome. Darlington suggests that the properties of polarisation during pachytene in Chorthippus and Stauroderus are due in part to the attraction between condensed parts of chromosomes. Based on these observations and others (Koul, 1964), one can only conclude that the orientation of chromosomes in the pachytene nucleus is partially dependent on non-homologous interactions involving heterochromatin. Many of these associations are resolved by the time cells enter diplotene (Southern, 1967; Darlington, 1936) but some do persist. It is not surprising then that associations are seen between the $\mathrm{X}$ chromosome and the NO bivalent which is largely heterochromatic in Camula pellucida. Other associations that were observed (tables 1 and 2) are likely due to the centric heterochromatin which is present in all bivalents. These persistent associations are relics of more extensive associations which were present at earlier stages of meiosis.

It is clear that the addition of still more heterochromatin in the form of a supernumerary segment increases the number of non-homologous associations and thus alters the positional relationships of the chromosomes during meiotic prophase. The segmented small bivalent now lies in close proximity to the $\mathrm{X}$ chromosome or to the NO bivalent more frequently than if it were not segmented. It appears also that the presence of $\mathrm{B}$ chromosomes in Haplopappus spinulosus may alter positional relationships of pachytene chromosomes. Li and Jackson (1961) described specific associations between 
B chromosomes and two of four bivalents present during meiosis in this plant species.

Supernumerary heterochromatin in the form of B chromosomes or added chromosomal segments affects chiasma conditions at meiosis (John and Hewitt, 1965a, b, 1966, 1969; Jones and Rees, 1967; Westerman, 1969; Shaw, 1971). Heterochromatin has also been implicated in the interchromosomal control of genetic recombination or chiasma formation in other situations. Hewitt (1967) described a chromosomal interchange in the grasshopper Cibolacris parviceps which raised the chiasma frequency in all chromosomes. Special notice was taken of the fact that the interchange involved a considerable redeployment of heterochromatin within the cell. Heterochromatin has also been implicated in Drosophila melanogaster as a controlling factor in recombination (see Lucchesi and Suzuki, 1968 for review).

Much effort has been expended by various authors in proposing mechanisms and hypotheses to account for the many heterochromatin effects and other interchromosomal effects on recombination (Lucchesi and Suzuki, 1968). Hewitt (1967) divided these hypotheses and mechanisms into two categories, mechanical and physiological. Mechanical hypotheses suggest that the extra heterochromatin may interfere with chromosome pairing thus altering chiasma formation. As pointed out by Hewitt (1967), certain observations are difficult to reconcile on the basis of purely mechanical grounds. For example, the presence of two accessory chromosomes has the same effect as one (Hewitt and John, 1968; Jones and Rees, 1967), and there is no dosage effect with supernumerary segments in some species of grasshoppers (John and Hewitt, 1969). Rather, most authors appear to accept a physiological hypothesis. This hypothesis includes the idea of position effects and that heterochromatin acts indirectly by modifying gene action which leads to a change in the control of crossing-over. Indeed, Southern (1970) states: "it is now generally recognised that the influence of these additional chromosomes and segments can be ascribed to the one feature they all share in common ". "They are heterochromatic." " And it is through the modifying action that some heterochromatin appears to exert over the normal gene control system that we get an indirect effect on the level of recombination." Aside from such strong statements, the fact remains that although heterochromatin has been shown to be involved in the control of gene action in specific situations (Lewis, 1950; Lyon, 1962), it is impossible to do more than speculate on its role in regulating genes involved in recombination.

It may not be unreasonable to consider that heterochromatin may partially exert its effect on chiasma formation simply because it is "sticky" and thus alters the spatial relationships of chromosomes during meiotic prophase. It is highly probable that spatial relationships of chromosomes are important for normal regulatory functions to occur. One recent example which suggests this possibility comes from the work of Wimber and Steffenson (1973). They describe the situation in Drosophila melanogaster polytene chromosomes where a chromosome region involved in the synthesis of $5 \mathrm{~s}$ RNA is positioned in a specific relationship with the nucleolus. This is an excellent example of a correlation between functional and spatial relationships of nuclear elements. We could speculate that at pachytene of meiosis (at which time genetic recombination occurs) that spatial relation- 


\section{Plate I}

FIGs. 1 and 2.-Cells in diplotene showing the standard diplotene complement and nonhomologous associations of the X-NO type (open arrows). Closed arrows indicate the nucleolar organising bivalent and the two small bivalents.

FIGs. 3 and 4.-Cells in diplotene from segmented individuals showing non-homologous associations of X-S and NO-S $S_{1}$ types respectively (open arrows). $S_{1}$ and $S_{2}$ refer to the segmented small bivalent and the non-segmented small bivalent respectively.

FIG. 5.-Radial metaphase II configuration with 12 chromosomes (X present) from a nonsegmented individual.The two small chromosomes (arrows) show a 4-6 arrangement with respect to all other chromosomes.

FIG. 6.--Radial metaphase II configuration with 11 chromosomes ( $\mathrm{X}$ absent) from a segmented individual. $S_{1}$ and $S_{2}$ are the segmented and non-segmented small chromosomes respectively (arrows). This cell resulted from an equational separation of the segmented small bivalent at anaphase $\mathrm{I}$. The two small chromosomes $\left(\mathrm{S}_{1}\right.$ and $\left.\mathrm{S}_{2}\right)$ show a 1-8 arrangement with respect to all other chromosomes. 


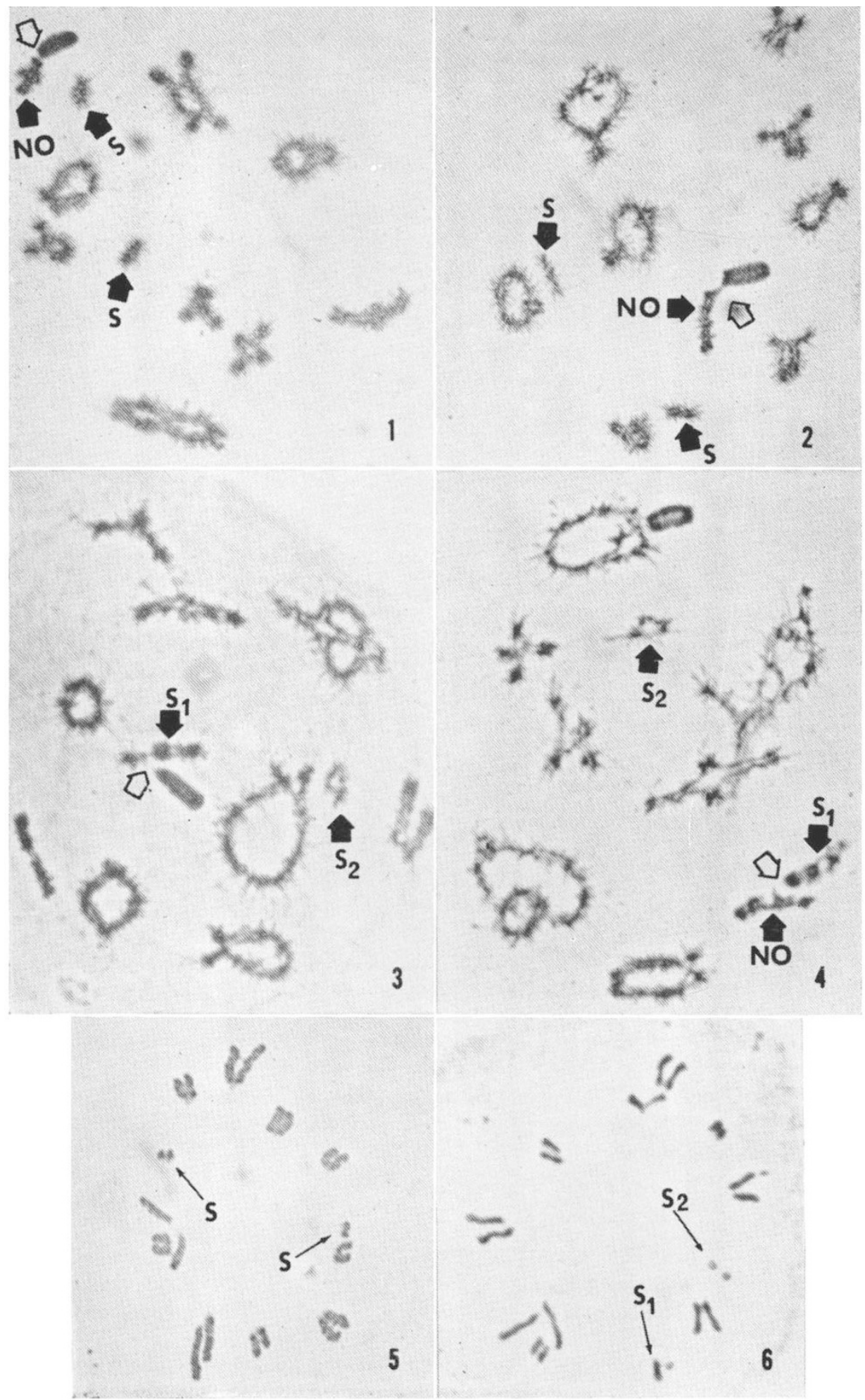


ships of the bivalents may be important for the regulation of this process. Thus an alteration in these spatial relationships may result in an alteration of regulatory processes governing chiasma formation.

The supernumerary heterochromatic segment appears to have no effect on the arrangement of chromosomes at metaphase II of meiosis. The non-homologous associations appear to be resolved by the end of prophase of meiosis, and the present investigation indicates no residual effects of these associations are apparent at metaphase II. The small chromosomes are behaving independently of all other chromosomes in their positioning on the radial metaphase II plate in both segmented and non-segmented individuals. This observation is in agreement with that of Nur (1973) who demonstrated that the large chromosomes in the grasshopper Melanoplus femur-rubrum are randomly arranged in the metaphase II configuration.

Acknowledgments. - I wish to thank Mr Alan Hamilton for his indentification of the species. This work was supported in part by a grant from the National Science Foundation (05-074380) and a Arizona State University Grant-in-Aid.

\section{REFERENCES}

DARLINGTON, C. D. 1936. Crossing-over and its mechanical relationships in Chorthippus and Stauroderus. 7. Genet., 33, 465-500.

HEWrT, G. M. 1967. An interchange which raises chiasma frequency. Chromosoma (Berl.), $21,285-295$.

HEWITT, G. M., AND JOHN, B. 1968. Parallel polymorphism for supernumerary segments in Chorthippus parallelus (Zetterstedt). I. British populations. Chromosoma (Berl.), 25, 319-342.

JOHN, B., AND HEWrTT, G. M. 1965a. The B-chromosome system of Myromeleotettix maculatus (Thumb.). I. The Mechanics. Chromosoma (Berl.), 16, 548-578.

JoHn, B., AND HEWITT, G. M. 1965b. The B-Chromosome system of Myromeleotettix maculatus (Thumb.). II. The statics. Chromosoma (Berl.), 17, 121-138.

JOHN, B., AND HEWTT, G. M. 1966. A polymorphism for supernumerary segments in Chorthippus parallelus. Chromosoma (Berl.), 18, 254-271.

JOHN, B., AND HEWTTT, G. M. 1969. Parallel polymorphism for supernumerary segments in Chorthippus parallelus (Zetterstedt). III. The Ashurst population. Chromosoma (Berl.), 28, 73-84.

JONES, N. R., AND REES, H. 1967. Genotypic control of chromosome behaviour in rye. XI. The influence of B chromosomes on meiosis. Heredity, 22, 333-347.

Koul, A. K. 1964. Heterochromatin and non-homologous associations in Coix aquatica. Chromosoma (Berl.), 15, 243-245.

LEWIS, E. B. 1950. The phenomenon of position effect. Advances in Genetics, 3, 73-115.

LI, NING, AND JACKSON, R. C. 1961. Cytology of supernumerary chromosomes in Haploppapus spinulosus SSP. Cotula. Am. 7. Botany, 48, 419-426.

LUCCHESI, J. C., AND sUZUKI, D. T. 1968. The interchromosomal control of recombination. Annual Review of Genetics, 2, 53-86.

LYon, M. F. 1962. Sex chromatin and gene action in mammalian X chromosome. Amer. 7. Hum. Genet., 14, 135-148.

NUR, U. 1973. Random arrangement of chromosomes in a radial metaphase configuration. Chromosoma (Berl.), 40, 273-267.

SHAW, D. D. 1970. The supernumerary segment system of Stethophyma. I. Structural basis. Chromosoma (Berl.), 30, 326-343.

SHAw, D. D. 1971. The supernumerary segment system of Stethophyma. II. Heterochromatin polymorphism and chiasma variation. Chromosoma (Berl.), 34, 19-39.

SOUTHERN, D. I. 1967. Pseudo-multiple formation as a consequence of prolonged nonhomologous chromosome association in Metrioptera brachyptera. Chromosoma (Berl.), 21, 272-284. 
SOUTheRN, D. I. 1970. Polymorphism involving heterochromatic segments in Metrioptera brachyptera. Chromosoma (Berl.), 30, 154-168.

VANDERLYN, L. 1949. The heterochromatin problem in cytogenetics as related to other branches of investigation. Bot. Rev., 15, 507-582.

Westerman, M. 1969. Parallel polymorphism for supernumerary segments in Chorthippus parallelus (Zetterstedt). II. French populations. Chromosoma (Berl.), 26, 7-21.

WIMBER, D. E., AND STEFFENSON, D. M. 1973. Localization of gene function. Annual Reviews of Genetics, Vol. 7, in press. 